with theoretical treatments of problems.

It was particularly pleasing to find a chapter devoted to scattering of electromagnetic radiation (written by S. D. Dover), since some understanding of this phenomenon at a fundamental level is becoming more important as laser technology expands the possibilities of measuring molecular properties on very short time scales.

The book will provide a useful reference text for undergraduates requiring guidance in the application of chemical thermo- dynamics to describing macromolecular properties. Further, like Professor C. Tanford's well known text on a similar topic (The Physical Chemistry of Macromolecules; Wiley, 1961), the content is such that it will also be of value to postgraduates with an interest in the subject.

S. P. Spragg is Senior Lecturer in Physical Chemistry at the University of Birmingham, $U K$, with research interests in the solution properties of biological macromolecules.

\title{
New membranes for old
}

\section{Harvey Lodish}

Cell Membranes and Viral Envelopes. Edited by H. A. Blough and J. Tiffany. 2 volumes, pp.848. (Academic: 1980.) Both volumes $£ 40, \$ 92$.

Most lipid-containing animal viruses bud from either the plasma membrane or internal membranes of infected cells. Much of our knowledge of the structure and assembly of membrane components has come from the use of defined virus model systems. These two volumes represent a noble and needed attempt to bring together reviews on the structure and function of both viral and cellular membranes and their constituents. There are chapters, written by recognized experts, on the basic physical and microscopic techniques used in membrane research, and on the biochemistry of viral and cellular membrane lipids, proteins and carbohydrates. In addition there are contributions on the structure and assembly of particular groups of viruses influenza virus, retroviruses, Herpes virus and rhabdoviruses - though, oddly, none on the paramyxoviruses or arboviruses.

Most of the contributions to these volumes were written in 1974 and 1975 . The end result is that the coverage of publications during the past five years is very erratic. Incredibly, the two chapters written by the editors contain references to very few articles published after 1976. What is worse, the editors apparently exercised little direction over the content of individual chapters, nor did they attempt to rewrite, up-date, or interrelate them. The predictable result is extensive redundancy of data and confusion between chapters.

As one example, the partial sequence of glycophorin used in the chapter on the structure and function of membrane proteins is taken from the 1971 preliminary report; there is no reference to the complete sequence published in 1975 or to the 1978 revised sequence. Oddly, the complete sequence is contained in the following chapter, "Carbohydrates in the Cell
Membrane". Further, in no contribution is there mention of the techniques of fluorescence photobleach recovery, now probably the most widely used method for the determination of the extent and rate of lateral diffusion of cell surface components.

The chapter on carbohydrates of viral envelopes was written in 1974, and is very dated, but some of the more recent structural work is contained in the following chapter, "Glycosylation of Viral Envelope Components". None of the contributions discusses recent work on the importance of proteolytic cleavages in the maturation of viral glycoproteins, such as the influenza haemagglutinin HA or the paramyxovirus fusion protein $\mathrm{F}$. The contribution "Synthesis of Viral Proteins" was also written in 1974-1975, before the site of synthesis of viral glycoproteins in the rough endoplasmic reticulum was known; this chapter, unfortunately, is now largely of historical interest only. Like several others, it contains a one-page addendum which mentions some published work up to the beginning of 1977, but there still remains an inexcusable three-year delay before even this was published.

Some of the individual reviews dealing with more recent developments are of high quality. Many others would have been quite useful had they been published within a year or so of writing, surely a more reasonable lag time. These include those on virus receptors; on influenza virus; on structure and on synthesis of membrane and viral lipids; and on membrane changes in virally transformed cells. The fields covered by this book are expanding very rapidly; as a consequence, these reviews will not be of much value to the contemporary student or researcher. It is indeed unfortunate that the considerable effort expended in writing this book has been largely wasted, as current reviews of these topics would be valuable.

Harvey Lodish is Professor of Biology at the Massachusetts Institute of Technology, Cambridge, Massachusetts.

\section{Geothermal maps}

\author{
Philip England
}

Atlas of Subsurface Temperatures in the European Community. Compiled by R. Haenel with co-authors. Large format, pp. $36+43$ maps. Commission of the European Communities/Th. Schäfer: Hannover, 1980.) DM 120.

THE production of subsurface temperature maps for an area the size of the European Economic Community is an undertaking that requires a degree of faith. If it can be assumed that the available, sparsely distributed, temperature and thermal conductivity data adequately characterize the near-surface heat flow of the region (and that this is not perturbed by fluid motion), then it requires only a knowledge of the subsurface geology, and of the thermal conductivity and heat generation of the major lithologies, to extrapolate measured temperatures outward and downwards to make the kind of map this book contains.

These maps are each about $40 \mathrm{~cm} \times 50$ $\mathrm{cm}$ in size. Seven are 1:5,000,000 maps of subsurface temperature distributions beneath Europe at depths between $500 \mathrm{~m}$ and $5 \mathrm{~km}$; six show subsurface temperatures at $1 \mathrm{~km}$ for the countries of the EEC; and some 20, with scales of between

\section{Bring Your Library Up-to-Date With This ANS Edition ... Nuclear Energy in Germany}

\author{
Winnacker/Wirtz
}

\section{$6 \times 9$ hardbound edition $\$ 37.00$}

\section{American Nuclear Society \\ 555 North Kensington Avenue La Grange Park, IL 60525 USA}

Please take my order for books.

[ ] Payment in full enclosed.

$\square$ Bill me and I accept postage and handling charges.

Name

Org.

Stree

City

State Zip

Circle No. 01 on Reader Enquiry Card. 